\title{
Rheumatologists in the COVID-19 era: will there be a new role for the rheumatologist in the care of rheumatic patients?
}

\author{
Jorge Morales-Torres ${ }^{1,2}$ [D $\cdot$ Francisco Javier Aceves-Ávila ${ }^{3}$
}

Received: 9 July 2020 / Revised: 26 August 2020 / Accepted: 27 August 2020 / Published online: 5 September 2020

(C) International League of Associations for Rheumatology (ILAR) 2020

\section{Introduction}

The global disease burden of coronavirus disease 2019 (COVID-19) has risen to unprecedented levels never seen in this generation. A World Health Organization (WHO) situation report on July 4, 2020, presented a global figure of $10,992,324$ cases, 523,011 deaths, and 212,326 new cases in the previous $24 \mathrm{~h}$, with the Americas on the top of both confirmed and new cases as well as new deaths. Its distribution between countries and regions show big differences. While new cases and deaths have decreased sharply in countries like China and tend to decrease notably in some other countries (like Spain, Italy, and Germany), they are still high in several regions [1]. It is hard to foresee a near end for this ordeal, and one possible scenario is that COVID-19 will become an endemic condition [2]. Therefore, sociopolitical and daily life adaptations will be required, and the society will need to find ways to coexist with it, until a vaccine or cure become available.

The spectrum of clinical manifestations of the infection from SARS-CoV-2 varies from asymptomatic persons or with very mild disease to patients with severe acute respiratory syndrome, with a high mortality rate [3]. This group has overwhelmed health facilities and forced adaptations and redirections of resources and has exposed the limitations and inequities of most health systems poorly prepared to face this kind of global threat. The socioeconomic implications of this

Jorge Morales-Torres

jorgitomorales@prodigy.net.mx

1 Hospital Aranda de la Parra, Hidalgo 329, 37000 Leon, GTO, Mexico

2 Morales Vargas, Centro de Investigación, Blvd. Adolfo López Mateos 218-D Poniente, 37000 Leon, GTO, Mexico

3 Unidad de Artritis y Reumatismo, Colomos 2292, Col Providencia, 44620 Guadalajara, JAL, Mexico pandemic are easy to understand as social distancing, selfisolation, and travel restrictions have brought a significant reduction in jobs in every sector of the economy. Also, with schools closed and the demand for several goods sharply decreased (except probably for the increased need for medical supplies and food products), it is easy to recognize the signs of a severe economic impact looming ahead [4]. Some observers have pointed to accumulating impacts of this crisis beyond the immediate morbidity, mortality, and sequelae of COVID-19 and warn of the consequences of delaying care for nonCOVID medical and surgical emergencies due to limited resources: of the impact of interrupted care for many chronic conditions and even the cumulative effects of fear and helplessness, the economic injury and burnout of both health professionals, and the society in general [5]. It is in this context that we believe several pragmatic adaptations will be needed in the practice of medicine. Here we discuss some aspects related to rheumatology.

\section{How does COVID-19 affect rheumatology practice?}

Patients with inflammatory and autoimmune diseases are often complicated with several comorbidities. Among them, infections of diverse types, serious infections, those requiring hospitalization, and those associated with mortality are more common in this group of patients [6-11]. Susceptibility of inflammatory/autoimmune diseases to infections seems to be related to identifiable factors, including severity of the disease, smoking, comorbidities, and treatment with immunosuppressants and particularly glucocorticoids, especially in high doses [6-9]. Interestingly, starting a treatment with anti-TNF apparently does not increase the risk for severe infection on top of what is seen with traditional treatments, although there may be differences between different specific agents [11]. Several infections preventable by vaccination (including influenza and pneumococcal disease) are more common in patients with 
autoimmune and inflammatory conditions [12], making their prevention mandatory through adequate vaccination protocols $[12,13]$. With this background, it is reasonable to have concerns regarding the possibility of an increased susceptibility of rheumatic patients to be complicated with COVID-19.

This relationship has been the subject of numerous papers: from articles on concern about the impact of this infection on patients with rheumatic and musculoskeletal disorders [14] to papers dealing with case reports of rheumatic patients and COVID-19 [15]. Drug shortages and altered patterns of health care have been concerning since the early days of this pandemic [16]. Several reports point to the fact that prevalence and severity of COVID-19 seem not to be higher in rheumatic patients, even those under treatment with immunosuppressants, biologics, and small molecules, than those found in the general population [17-20]. This could be different for some conditions. Two case series report on patients with systemic lupus erythematosus and COVID-19. The frequency of severe disease appeared to be higher than expected in these patients [21,22].

Reviews and editorials discuss the foreseeable adjustments and adaptations to continue providing adequate medical care of patients with rheumatic and musculoskeletal diseases, including the possibility of drug shortages, given the empirical use of agents like hydroxychloroquine, IL-6 receptor inhibitors, and baricitinib to treat severe cases of infection by SARS-CoV-2 $[23,24]$. A promising initiative has been the launching of an international effort to create a registry for cases of rheumatic patients affected by this virus, the COVID-19 Global Rheumatology Alliance (C19-GRA), to generate rapid data to aid in the information on care of such patients. Its initial descriptive report of 110 cases, collected in 1 week [25], was soon followed by the organization of the C19-GRA Patient Experience Survey (at www.rheum-covid.org/patient-survey), aimed to collect anonymously information directly from the patients, with or without the infection, to explore the way this pandemic has altered their physical and mental health, behavior, and ability to continue the attention to their disease. By April 16, 2020, it had collected responses from 9541 patients. Information promises to become a rich source of understanding of current aspects of this pandemic in rheumatology [26]. Another report of this alliance describes the outcome of 600 patients collected from 40 countries, where $46 \%$ required hospitalization and 9\% died. Diseasemodifying biologics, targeted therapies, and nonsteroidal antiinflammatory drugs did not increase the chance to require hospitalization, while prednisone dose $\geq 10 \mathrm{mg} /$ day, older age, and comorbidities increased such risk [27]. A survey performed in 500 patients from Greece, with diverse rheumatologic conditions, found that only $2.2 \%$ stopped their medication fearing infectious complications and 3.8\% discontinued treatment because of drug shortage, mainly hydroxychloroquine [28]. The risk of relapse after discontinuation of several drugs should lead to educational efforts for both physicians and patients to avoid withdrawals [29]. Among the flood of publications on COVID19 , some published guidelines stand tall, aiming to unify concepts on care of rheumatic patients during this pandemic. They come from consensus organized by national and regional societies of rheumatology, and, although preliminary, they support several common points, including the need to prevent infection from SARS-CoV-2 through general measures, including social distancing, proper use of masks, and hand and surface sanitization. These measures require some adaptations to manage rheumatic diseases while avoiding risks of contagion for both patients and health professionals. They include some recommendations to manage COVID-19 in the context of rheumatic and musculoskeletal diseases and on prevention of infections different from SARS-CoV-2 [30-32]. They are explicitly considered starting points, appearing before there is a robust body of evidence, guided by the need to help rheumatologists to face the anxiety and uncertainties of treatment implications of patients during the pandemic.

Beyond the inflammatory and autoimmune diseases, some adaptations have been proposed to guide in the management of osteoarthritis [33] and osteoporosis [34]. They include common-sense measures to preserve a reasonably good diet and exercise adapted to times of limited mobility and access to the usual facilities. They insist on preventive measures against the infection and the continuation of therapy. Strategies to advice on their control remotely may be particularly useful in these conditions.

Patients experience considerable negative feelings to attend hospitals, lab and X-ray facilities, medical offices, and emergency wards, even when facing severe acute health problems. Fearing contagiousness, many patients opt for avoiding those sites ("COVID-19 outweighs my health problems"), opening the need to find adaptations to regular medical care [35]. Health systems that functioned optimally in "normal" times practically collapsed with the number of patients requiring urgent care for COVID-19. Full hospitals were restricted only to treat this condition, and the workforce redirected to face that threat, thus limiting access to several interventions for chronic diseases (elective surgery, infusion centers, etc.) and for other acute conditions, including non-COVID-19 infections [36]. Economic impact on patients and their families may limit their access to some components of medical care in the near future [4].

\section{Pragmatic approaches for rheumatology in the times of COVID-19}

\section{Personal and associate's protection}

As diverse infectious diseases have come and gone through centuries, we have a hint of how this actual threat may behave in the next decades. It seems clear that it will not just enter history and disappear, like other epidemic conditions in the 
past [37]. Given the known characteristics of the SARS-CoV2 and the measured immune response in those recovered, it is still uncertain if an effective vaccine or pharmacological treatment will be available in a near future [38]. Thus, like in most infectious conditions, prevention is the most reasonable approach, both for diminishing the risk of patients attending a site of potential concentration of cases such as a medical office and for protecting physicians from the inevitable exposition to cases.

Precise recommendations have been issued and are under regular revisions by the World Health Organization (WHO). The documents can be consulted in the official WHO page for updates and specific publications [39]. Health institutions and regulatory offices of each national government are also frequently revised so local guidelines must be attentively followed for changes in local practices.

Persons infected with SARS-CoV-2 have a potential to carry and shed the virus even when asymptomatic. The virus remains viable and infectious for hours in aerosols and for days in some surfaces [40], providing a rationale for some efforts to mitigate the pandemic. Revised processes for thorough cleaning of surfaces and hands and using alcohol-based gels, chemical antiviral substances (including alcohol, chlorine bleach, ammonium quaternary compounds, triclosan, pine oil, among others), physical barriers, and ultraviolet light are the most plausible methods to limit the spread of the infection $[41,42]$. We will be dealing with this new situation in offices not designed for this purpose; therefore, physical modifications will be necessary in the new design of medical offices. It will not be practical or easy to apply for everyone.

There must be visual aids, easily understandable encouraging washing of hands, wearing protective masks, and use of alcohol-based gels. All these implements must be on sight and at hand in the common areas.

Keeping a safe distance between patients in waiting rooms should be considered mandatory. The actual recommendation is at least $1 \mathrm{~m}$ between each person in waiting areas. Some modifications should be made in common areas, where supporting personnel is in potential contact with patients. Secretaries, nurses collecting data, and other counselors (nutritionists, etc.) should be protected from potential exposure by see-through screens if a safe distance cannot be guaranteed. They limit transmission via droplets and aerosols, as well as physical contact, and are easily cleaned.

Even educational material for patients will change, most probably as information through electronic media. Magazines, newspapers, and even the fabric of the chairs in the waiting rooms must be considered as fomites. It is advisable to have materials easily sanitized.

Physicians must grow acquainted to continuous use of goggles, protective masks, and uniforms even in their office. Medical masks are defined in WHO official documents as "surgical or procedure masks that are flat or pleated; they are affixed to the head with straps that go around the ears or head or both." They are required to provide adequate breathability and fluid penetration resistance. A systematic review and meta-analysis of existing evidence concluded on the efficacy of inter-person distancing of 1 to $2 \mathrm{~m}$ and the use of face masks (N95 or similar respirators in medical settings and cotton or surgical masks in the community). Eye protection may provide additional protection [43].

\section{Reorganization of appointments to limit crowding}

Appointments for medical consultations should be strongly encouraged, and if the patient has no disabilities requiring physical assistance, they should stay alone in the waiting room. Accompanying persons not essential for assistance should be encouraged to remain off the facilities. Time between appointments should be increased according to the necessity of cleaning the common contact areas in the medical office between patients. This will also permit that the next patient will be alone or with no more than one other person in the waiting room. In some institutions, waiting rooms are shared by diverse physicians, so physical modifications are strongly advised to allow enough distance between patients in the waiting room, and physicians should consider the proper modifications of scheduling necessary not to have more patients summoned at the same time than the proper capacity of the waiting room to maintain a safe distance between patients. Every patient scheduling an appointment should be informed on the need to wear a surgical mask, avoid accompanying crowds, and, when arriving to the site, to have hands sanitized.

\section{Lab and imaging remote access through electronic media}

Lab and image results will be an issue. Unfortunately, not all places can guarantee good quality internet in a regular practice to access them. The use of computers and diverse electronic media to evaluate clinical images may be compromised in such places. Efforts should be made to lessen the need for visits only to review results by using electronic media. Today's common practice of carrying all their historical results will be unavoidable in some cases. These are potential sources for contamination of surfaces.

\section{Telehealth}

Medical practice will change in the foreseeable future. Working from home and providing diverse services by remote positions is a regular practice in business in all branches of commerce and industry. Although we have used remote clinical consultations, mostly by telephone, for decades now, it is not a regular practice and not all physicians or patients feel comfortable with it. It is 
advisable to use new technologies to keep in touch with our patients. The use of internet and associated technologies implies a new way of comprehending our relationship with our reality [44]. In XVIII century, distant consultations by regular mail were a common practice in England. Physical examination was not the expected maneuver by physicians up until the first half of the twentieth century [45].

Distant consultations are part of our new paradigms in technology, but they imply a new way of thinking and comprehending medical practice. Due to the new risks of contagion, they must be encouraged from now on in the regular care of rheumatic patients. For patients on regular control, a video conference may be enough to detect any potential trouble that could deserve a presential consultation. For first-time patients, in which a diagnosis is still lacking, an initial distant consultation can give a very precise appreciation about the need for a presential consultation and the screening lab results and images needed to achieve a diagnosis. Several instruments have been proven useful to evaluate discrete clinical components, including swollen and tender joints, through patient's selfassessment [46-48]. Newer instruments provide elements to predict what the direct musculoskeletal examination by an experienced physician will find [49]. The empathic component of medical contact is maybe one of the issues to look up in these interactions. A systematic review of telemedicine for rheumatic patients found a high degree of feasibility and satisfaction for interactions for consultation, treatment, and monitoring of disease activity [50]. Remote health interactions have limitations. Legal aspects of some prescriptions, medical responsibility, realistic approaches to billing, and other practical points have been neglected for a long time. The SARS-CoV-2 pandemic has forced some countries to promote fast administrative and legal support to implement telehealth as an option to prevent attendance to places with a higher risk of contagion [51]. Some ad hoc companies offer instruments to perform diverse telehealth interventions for a fee, but some free instruments are available even for persons with limited computing skills.

\section{Resources to promote awareness and preventive approaches against COVID-19 among patients}

Awareness of the importance of the risks of COVID-19 is less than optimal among many segments of the population, despite the abundant publications on this point. Every opportunity to contact a patient or their families, either personally or via telehealth instruments, should become an occasion to reinforce the information on preventive measures. Insisting on social distancing, the correct use of cloth or surgical masks and eye protection while in public, and frequent sanitization of hands will never be overstated. Published preliminary guidelines on management of rheumatic patients during this pandemic include the need to keep them informed, with best available evidence [30-34].

\section{Keeping afloat (and updated) on the flood of COVID- 19 literature}

A non-exhaustive search in PubMed on July 4, 2020, yielded 28,974 papers under the search term "COVID-19" not including those under terms like "coronavirus" or "SARS-CoV-2." It is probably a record-breaking mark in only 5 months of the pandemic [52]. For comparison, the year with more publications on HIV-AIDS (2014) reached 7301 papers included in PubMed. It is impossible to read them all and to extract what is relevant for an ongoing health disaster. The urgent need for approaches to deal with COVID-19 has brought a rush to publish, with expedited time for reviews. A sobering reminder of the need to hold on to scientific rigor in research comes from the fact that the rate of retracted papers on COVID-19 practically doubles those seen in other topics [53], calling for a responsible commitment from researchers, authors, editors, and reviewers to maintain quality of what will appear published. Readers should keep a critical view of scientific papers and probably a selective search for the subjects more related to their field of action. The use of instruments of artificial intelligence to select what to read could help in this pandemic "paper tsunami" [54]. Rheumatologists with limited informatic skills may always count with bulletins of scientific societies, a few major journals, and even with word of mouth (or tweets and messages) from trusted colleagues.

\section{Keeping contact with advances in rheumatology and colleagues through electronic media}

Progresses in the field of rheumatology keep flowing. With practically all major medical meetings canceled or postponed indefinitely in 2020, many have appeared as online events. Advances in several topics have been presented in "webinars" organized by medical societies and pharmaceutical industry. Although accessible and sometimes attractive, they have some practical limitations, ranging from access to internet to fatigue related to hours spent facing a screen. Electronic media may also facilitate contacts with colleagues and friends, while social and professional gatherings are restricted.

\section{Maintaining mental sanity}

Since the early days of SARS-CoV-2 pandemic, it has been evident that the outbreak has had several psychosocial impacts on patients, on the general population, and on health professionals. These include anxiety, depression, insomnia, anger, and fear and call for preventive strategies. Beyond the urgent need to prevent transmission and the treatment of severe cases, additional efforts will be needed to handle mental health issues $[4,5,55]$. As to health professionals, efforts to preserve mental sanity should include adequate personal protection gear, reasonable rest time, exercise, and leisure activities within 
Table 1 Key messages to manage rheumatic patients during COVID19 pandemic

1. Protection of physicians and health professionals

1.1. Safe distance in office

1.2. Protective devices (face masks, see-through screens, goggles)

1.3. Frequent hand washing and chemical sanitization of hands and exposed surfaces

1.4. Re-designing of offices and waiting rooms (ventilation, easily cleanable surfaces, and avoiding non-indispensable instruments and decoration, as potential fomites, etc.)

2. Reorganization of appointments to avoid crowding in waiting rooms and offices

3. Preferential access to laboratory results and imaging studies through electronic media, to limit visits

4. Strategies to implement telehealth and its use whenever possible to limit presential visits

5. Promote awareness and preventive measures against COVID-19, among patients, and identify those at higher risk from comorbidities

6. Implement strategies to follow relevant scientific information on the pandemic

7. Maintain contact with colleagues and advances in rheumatology, through electronic media

8. Do not dismiss mental health issues. Take preventive actions for its preservation

8.1. Be aware of the impact of these measures added to the burden of the rheumatic diseases on patients and their families

8.2. Be aware of the impact of these measures on your life and that of your colleagues and collaborators

the limitations of confinement. A reasonable economic stability and certainties of access to medical care when needed are also welcome.

Table 1 summarizes these key messages for the management of rheumatic patients in this pandemic.

\section{Conclusions}

The SARS-CoV-2 pandemic has impacted life in all aspects. Contagiousness for everyone and life-threatening disease for some patients have led to necessary adaptations in the provision of medical care. Limiting visits to medical offices and infusion centers, using instruments for telehealth, when possible and providing information and education on prevention of COVID-19 should be part of the new reality. Simultaneously, adequate protection for health professionals and collaborators to prevent contagion, efforts to keep updated both about advances on COVID-19, and our field of interest and strategies to keep mental health afloat should be constant tasks. Knowledge on this field flows at a vertiginous pace, and therefore it is advisable to be optimistic, considering there will be answers for many of today's questions. Hopefully this will be soon.
Code availability NA

Authors' contributions Both authors originated the conception and design of the review. Both authors participated in gathering, analyzing, and interpreting the data; critical review of its intellectual content; and definitive approval of the final text.

Data availability NA

\section{Compliance with ethical standards}

Disclosures None.

Ethics approval NA

Consent to participate NA

Consent for publication NA

\section{References}

1. World Health Organization (2020) Coronavirus disease (COVID19). Situation report-166. https://www.who.int/docs/default-source/ coronaviruse/situation-reports/20200704-covid-19-sitrep-166.pdf? sfvrsn=6247972_2. Accessed July 4, 2020

2. Cobey A (2020) Modeling infectious disease dynamics. Science 368:713-714. https://doi.org/10.1126/science.abb5659

3. Ge H, Wang X, Yuan X, Xiao G, Wang C, Deng T, Yuan Q, Xiao $X(2020)$ The epidemiology and clinical information about COVID-19. Eur J Clin Microbiol Infect Dis 39:1011-1019. https://doi.org/10.1007/s10096-020-03874-Z

4. Nicola M, Alsafi Z, Sohrabi C, Kerwan A, Al-Jabir A, Iosifidis C, Agha M, Agha R (2020) The socio-economic implications of the coronavirus pandemic (COVID-19): a review. Int J Surg 78:185193. https://doi.org/10.1016/j.ijsu.2020.04.018

5. Kohli P, Virani SS (2020) Surfing the waves of the COVID-19 pandemic as a cardiovascular clinician. Circulation 142:98-100. https://doi.org/10.1161/CIRCULATIONAHA.120.047901

6. Doran MF, Crowson CS, Pond GR, O'Fallon W, Gabriel SE (2002) Frequency of infection in patients with rheumatoid arthritis compared with controls: a population-based study. Arthritis Rheum 46: 2287-2293. https://doi.org/10.1002/art.10524

7. Franklin J, Lunt M, Bunn D, Symmons D, Silman A (2007) Risk and predictors of infection leading to hospitalisation in a large primary-care-derived cohort of patients with inflammatory polyarthritis. Ann Rheum Dis 66:308-312. https://doi.org/10. 1136/ard.2006.057265

8. Gabriel SE, Michaud K (2009) Epidemiological studies in incidence, prevalence, mortality, and comorbidity of the rheumatic diseases. Arthritis Res Ther 11(3):229. https://doi.org/10.1186/ar2669

9. Matsumoto Y, Sada K, Takano M et al (2011) Risk factors for infection in patients with remitted rheumatic diseases treated with glucocorticoids. Acta Med Okayama 65:329-334

10. Mehta B, Pedro S, Ozen G, Kalil A, Wolfe F, Mikuls T, Michaud K (2019) Serious infection risk in rheumatoid arthritis compared with noninflammatory rheumatic and musculoskeletal diseases: a US national cohort study. RMD Open 5:e000935. https://doi.org/10. 1136/rmdopen-2019-000935

11. Grijalva CG, Chen L, Delzell E, Baddley JW, Beukelman T, Winthrop KL, Griffin MR, Herrinton LJ, Liu L, OuelletHellstrom R, Patkar NM, Solomon DH, Lewis JD, Xie F, Saag $\mathrm{KG}$, Curtis JR (2011) Initiation of tumor necrosis factor- $\alpha$ 
antagonists and the risk of hospitalization for infection in patients with autoimmune diseases. JAMA 306:2331-2339. https://doi.org/ 10.1001/jama.2011.1692

12. Furer V, Rondaan C, Heijstek M, van Assen S, Bijl M, AgmonLevin N, Breedveld FC, D'Amelio R, Dougados M, Kapetanovic MC, van Laar JM, Ladefoged de Thurah A, Landewé R, Molto A, Müller-Ladner U, Schreiber K, Smolar L, Walker J, Warnatz K, Wulffraat NM, Elkayam O (2019) Incidence and prevalence of vaccine preventable infections in adult patients with autoimmune inflammatory rheumatic diseases (AIIRD): a systemic literature review informing the 2019 update of the EULAR recommendations for vaccination in adult patients with AIIRD. RMD Open 5(2): e001041. https://doi.org/10.1136/rmdopen-2019-001041

13. Glück T, Müller-Ladner U (2008) Vaccination in patients with chronic rheumatic or autoimmune diseases. Clin Infect Dis 46: 1459-1465. https://doi.org/10.1086/587063

14. Figueroa-Parra G, Aguirre-Garcia GM, Gamboa-Alonso CM, Camacho-Ortiz A, Galarza-Delgado DA (2020) Are my patients with rheumatic diseases at higher risk of COVID-19? Ann Rheum Dis:annrheumdis-2020-217322. https://doi.org/10.1136/ annrheumdis-2020-217322

15. Cheng C, Li C, Zhao T, Yue J, Yang F, Yan Y, Liu X (2020) COVID-19 with rheumatic diseases: a report of 5 cases. Clin Rheumatol 39:2025-2029. https://doi.org/10.1007/s10067-02005160-x

16. Michaud K, Wipfle K, Shaw Y et al (2020) Experiences of patients with rheumatic diseases in the US during early days of the COVID19 pandemic. ACR Open Rheumatol 2:335-343. https://doi.org/10. $1002 /$ acr2.11148

17. Quartuccio L, Valent F, Pasut E, Tascini C, DeVita S (2020) Prevalence of COVID-19 among patients with chronic inflammatory rheumatic diseases treated with biologic agents or small molecules: a population-based study in the first two months of COVID19 outbreak in Italy. Joint Bone Spine. https://doi.org/10.1016/j. jbspin.2020.05.003

18. Favalli EG, Mont S, Ingegnoli F, Balduzzi S, Caporalli R, Montecucco C (2020) Incidence of COVID-19 in patients with rheumatic diseases treated with targeted immunosuppressive drugs: what can we learn from observational data? Arthritis Rheum. https://doi.org/10.1002/art.41388

19. Sanchez-Piedra C, Diaz-Torne C, Manero J, Pego-Reigosa JM, Rúa-Figueroa Í, Gonzalez-Gay MA, Gomez-Reino J, AlvaroGracia JM, BIOBADASER study group (2020) Clinical features and outcomes of COVID-19 in patients with rheumatic diseases treated with biological and synthetic targeted therapies. Ann Rheum Dis 79:988-990. https://doi.org/10.1136/annrheumdis2020-217948

20. Monti S, Balduzzi S, Delvino P, Bellis E, Quadrelli VS, Montecucco C (2020) Clinical course of COVID-19 in a series of patients with chronic arthritis treated with immunosuppressive targeted therapies. Ann Rheum Dis 79:667-668. https://doi.org/ 10.1136/annrheumdis-2020-217424

21. Mathian A, Mahevas M, Rohmer J, Roumier M, Cohen-Aubart F, Amador-Borrero B, Barrelet A, Chauvet C, Chazal T, Delahousse M, Devaux M, Euvrard R, Fadlallah J, Florens N, Haroche J, Hié M, Juillard L, Lhote R, Maillet T, Richard-Colmant G, Palluy JB, Pha M, Perard L, Remy P, Rivière E, Sène D, Sève P, MorélotPanzini C, Viallard JF, Virot JS, Benameur N, Zahr N, Yssel H, Godeau B, Amoura Z (2020) Clinical course of coronavirus disease 2019 (COVID-19) in a series of 17 patients with systemic lupus erythematosus under long-term treatment with hydroxychloroquine. Ann Rheum Dis 79:837-839. https://doi.org/ 10.1136/annrheumdis-2020-217566

22. Wallace B, Washer L, Marder W, Kahlenberg JM (2020) Patients with lupus with COVID-19: University of Michigan experience.
Ann Rheum Dis:annrheumdis-2020-217794. https://doi.org/10. 1136/annrheumdis-2020-217794

23. Favalli EG, Ingegnol F, De Lucia O et al (2020) COVID-19 infection and rheumatoid arthritis: faraway, so close! Autoimmun Rev 102523:102523. https://doi.org/10.1016/j.autrev.2020.102523

24. McInnes IB (2020) COVID-19 and rheumatology: first steps towards a different future? Ann Rheum Dis 79:551-552. https://doi. org/10.1136/annrheumdis-2020-217494

25. Gianfrancesco MA, Hyrich KL, Gossec L, Strangfeld A, Carmona L, Mateus EF, Sufka P, Grainger R, Wallace Z, Bhana S, Sirotich E, Liew J, Hausmann JS, Costello W, Robinson P, Machado PM, Yazdany J, COVID-19 Global Rheumatology Alliance Steering Committee (2020) Rheumatic disease and COVID-19: initial data from the COVID-19 Global Rheumatology Alliance provider registries. Lancet Rheumatol 2:e250-e253. https://doi.org/10.1016/ s2665-9913(20)30095-3

26. Sirotich E, Dillingham S, Grainger R, Hausmann JS (2020) Capturing patient-reported outcomes during the COVID-19 pandemic: development of the COVID-19 Global Rheumatology Alliance Patient Experience Survey. Arthritis Care Res 72:871873. https://doi.org/10.1002/acr.24257

27. Gianfrancesco M, Hyrich KL, Al-Adely S et al (2020) Characteristics associated with hospitalisation for COVID-19 in people with rheumatic disease: data from the COVID-19 Global Rheumatology Alliance physician-reported registry. Ann Rheum Dis 79:859-866. https://doi.org/10.1136/annrheumdis-2020

28. Fragoulis GE, Evangelatos G, Arida A, Bournia VK, Fragiadaki K, Karamanakos A, Kravvariti E, Laskari K, Panopoulos S, Pappa M, Tektonidou MG, Sfikakis PP (2020) Treatment adherence of patients with systemic rheumatic diseases in COVID-19 pandemic. Ann Rheum. https://doi.org/10.1136/annrheumdis-2020-217935 annrheumdis-2020-217935

29. Schulze-Koops H, Krueger K, Specker C (2020) No advice to discontinue antirheumatic therapy for non-medical reasons in light of SARS-CoV- 2. Response to: 'Treatment adherence of patients with systemic rheumatic diseases in COVID-19 pandemic' by Fragoulis et al. Ann Rheum Dis. https://doi.org/10.1136/annrheumdis-2020217987 annrheumdis-2020-217987

30. Schulze-Koops H, Specker C, Iking-Konert C et al (2020) Preliminary recommendations of the German Society of Rheumatology (DGRh eV) for the management of patients with inflammatory rheumatic diseases during the SARS-CoV-2/Covid19 pandemic. Ann Rheum Dis. https://doi.org/10.1136/ annrheumdis-2020-217628

31. Landewe R, Machado P, Kroon F et al (2020) EULAR provisional recommendations for the management of rheumatic and musculoskeletal diseases in the context of SARS-CoV-2, April 2020 version. Ann Rheum Dis 79:851-858. https://doi.org/10.1136/ annrheumdis-2020-217877

32. Mikuls TR, Johnson SR, Fraenkl L et al (2020) American College of Rheumatology guidance for the management of adult patients with rheumatic disease during the COVID-19 pandemic. Arthritis Rheum 72:1241-1251. https://doi.org/10.1002/art.41301

33. Mobasheri A (2020) COVID-19, osteoarthritis and women's health. Case Rep Women's Health 27:e00207. https://doi.org/10.1016/j. crwh.2020.e00207

34. Girgis CM, Clifton-Bligh RJ (2020) Osteoporosis in the age of COVID-19. Osteoporos Int 71:1189-1191. https://doi.org/10. 1007/s00198-020-05413-0

35. Laura E, Wong LE, Hawkins JE, Langness S et al (2020) Where are all the patients? Addressing Covid-19 fear to encourage sick patients to seek emergency care. NEJM Catalyst. https://doi.org/10. 1056/CAT.20.0193

36. Sarzi-Puttini P, Ventura D, Antivalle M et al (2020) What did COVID-19 do to the organization of Italian rheumatology? The examples of Luigi Sacco University Hospital and the local health 
district of ATS Sardegna: the two faces of the same coin. Beyond Rheumatol 2(\#37)

37. Thwaites G, Taviner M, Gant V (1997) The English sweating sickness, 1485 to 1551. N Engl J Med 336:580-582

38. Calina D, Docea AO, Petrakis D et al (2020) Towards effective COVID-19 vaccines: updates, perspectives and challenges (Review). Int J Mol Med 46:3-16. https://doi.org/10.3892/ijmm. 2020.4596

39. World Health Organization (2020) COVID-19: Operational guidance for maintaining essential health services during an outbreak: interim guidance. 25 March 2020 https://apps.who.int/iris/handle/ 10665/331561. License: CC BY-NC-SA 3.0 IGO. Accessed 23 June 2020

40. van Doremalen N, Bushmaker T, Morris DH, Holbrook MG, Gamble A, Williamson BN, Tamin A, Harcourt JL, Thornburg NJ, Gerber SI, Lloyd-Smith JO, de Wit E, Munster VJ (2020) Aerosol and surface stability of SARS-CoV-2 as compared with SARS-CoV-1. N Engl J Med 382:1564-1567. https://doi.org/10. 1056/NEJMc2004973

41. Dellanno C, Vega Q, Boesenberg D (2009) The antiviral action of common household disinfectants and antiseptics against murine hepatitis virus, a potential surrogate for SARS coronavirus. Am J Infect Control 37:649-652. https://doi.org/10.1016/j.ajic.2009.03. 012

42. C-Hung C, C-Hsien C, C-Han C (2020) Can universal masking help with our recovery from the COVID-19 pandemic? Int J Surg 79:125-126. https://doi.org/10.1016/j.ijsu.2020.05.058

43. Chu DE, Aki EA, Duda S et al (2020) Physical distancing, face masks, and eye protection to prevent person-to-person transmission of SARS-Cov-2 and COVID-19: a systematic review and metaanalysis. Lancet 395:1973-1987. https://doi.org/10.1016/S01406736(20)31142-9

44. Baricco A (2019) The game. Editorial Anagrama S.A. $1^{\text {st }}$. ed. Barcelona

45. Shorter E (1985).Bedside manners. The troubled history of doctors and patients. Simon and Schuster, $1^{\text {st }}$. ed. New York

46. Anderson JK, Zimmerman L, Caplan L, Michaud K (2011) Measures of rheumatoid arthritis disease activity. Arthritis Care Res 63:S14-S36. https://doi.org/10.1002/acr.20621
47. Heegaard C, Dreyer L, Egsmose C, Madsen OR (2013) Test-retest reliability of the Disease Activity Score 28 CRP (DAS28-CRP), the Simplified Disease Activity Index (SDAI) and the Clinical Disease Activity Index (CDAI) in rheumatoid arthritis when based on patient self-assessment of tender and swollen joints. Clin Rheumatol 32:1493-1500. https://doi.org/10.1007/s10067-013-2300-9

48. Taylor PC (2020) Adopting PROs in virtual and outpatient management of RA. Nat Rev Rheum 16:477-478. https://doi.org/10. 1038/s41584-020-0449-6

49. Moreno-Torres LA, Ventura-Alfaro CE, Aceves-Avila FJ (2020) Cross-cultural adaptation and validation of the Gait, Arms, Legs, Spine locomotor screening test for detecting musculoskeletal disorders in Mexican adults. Int J Rheum Dis 00:1-7. https://doi.org/10. 1111/1756-185X.13849

50. Piga M, Cangemi I, Mathieu A, Cauli A (2017) Telemedicine for patients with rheumatic diseases: systematic review and proposal for research agenda. Semin Arthritis Rheum 47:121-128. https:// doi.org/10.1016/j.semarthrit.2017.03.014

51. https://www.cms.gov/newsroom/fact-sheets/medicaretelemedicine-health-care-provider-fact-sheet. Accessed 23 June 2020

52. https://pubmed.ncbi.nlm.nih.gov/?term=COVID-19. Accessed 23 June 2020

53. Yeo-Teh NSL, Tang BL (2020) An alarming retraction rate for scientific publications on coronavirus disease 2019 (COVID-19). Account Res:1-7. https://doi.org/10.1080/08989621.2020. 1782203

54. Brainard J (2020) New tools aim to tame pandemic paper tsunami. Science 368:924-925. https://doi.org/10.1126/science.368.6494. 924

55. Torales J, O'Higgins M, Castaldelli-Maia JM, Ventriglio A (2020) The outbreak of COVID-19 coronavirus and its impact on global mental health. Int J Soc Psychiatry 66:317-320. https://doi.org/10. $1177 / 0020764020915212$

Publisher's note Springer Nature remains neutral with regard to jurisdictional claims in published maps and institutional affiliations. 